\title{
Cognitive Behavior Therapy with Couples and Family Relationships
}

\author{
Aydın Söylemez ${ }^{1}$
}

\begin{abstract}
Family conflicts and violence between family members have an important place in divorce cases in the modern societies. However divorce rates rapidly increases day by day sharply. Family therapy is a kind of therapy is recognized by family therapist in order to solve problems and conflicts between family members. This study has a significance point because of offering strong solutions for family conflicts that is also a global issue in this contemporary time. Basically there are two purposes in this research generally: one of them is to explain the importance of family and couple therapy in the field of therapeutic approaches. The other purpose is to study couple conflicts and family relationship with cognitive behavior therapy. It was seen that cognitive theory and behavioral therapy can be discussed both separately and together depends on the problems in the family relationships. Finally, this review study offers a different perspective to the family and couple conflicts in order to solve it in the way of cognitive and behavior.
\end{abstract}

Keywords: Couple, family, cognitive and behavior therapy.

\section{INTRODUCTION}

Family is the smallest unit of a society. It arises from members who are connected to each other with a blood or a relative tie. The family members live in a home peacefully. Yet some characteristic features causes to some distinctness among the family members. If the members can not manage these distinct points, conflict happens between two or more than members in the family environment. Therapy is for this conflicts and problems among the family members. Family therapy is an efficient way of solving problems between family members. Moreover, there are so many therapeutic approaches in order to solve family and couple conflicts. Cognitive and behavioral therapy is one of effective methods in the solving communication and other matters within family.

\section{Cognitive behavior therapy (CBT)}

The philosophical fundamentals of Cognitive Behavior Therapy approach reaches to the Ancient Greek. The idea of the theory is based on the Plato's idealism. According to the Platonists, ideal forms were innate to the human mind and it is needed to educate thorough questioning method. This type of questioning was called as Socratic teaching method (Leahy, 1996).

Dattilio (2010) emphasizes that clients obtain a skill in order to solve their own problems effectively. Cognitive therapists evaluate the clients' thoughts, moods, behaviors, biology and environments in order to understand background of their problems. These terms is also related to Lazarus' BASIC-ID technique that is explained in his multimodal approach. According to his modal these five areas in the life are related to each other and they affect each other (Dryden \& Mytton, 1999). The cognitive therapists can intervene in just one area because one of them has an effect on the others. Changing one of five areas can affect also the other areas (Padelsky \& Greenberger, 1995).

\footnotetext{
${ }^{1}$ Doctorate student, Sakarya University, Psychological Services in Education, aydinsoylemez165@gmail.com
} 
It is understood in the above lines that cognitive behavior therapy is an approach that it uses the cognitions and behaviors when it helps the people who have pain from some problems and disorders psychologically. Cognitions are so important concept in the Beck's cognitive behavior theory because of its effectiveness on the people's behaviors. In other words cognitions and behaviors are connected to each other in both positive and negative ways.

\section{Couple and family therapy}

Bramlett \& Mosher (2002), asserted that 43 percent of couples has divorced in their 15 years marriage and they could not maintenance their second marriages with a high possibility. A research by Christensen \& Heavey (1999) showed that there is an increasing satisfaction level and success in the getting therapy as a couple when it compares to do not getting therapy (Dattilio, 2010).

These and other statistical research's results prove that there are big problems in the area of family. Therapy disciplines should give a high importance to family and relationships between its members because it is the fundamental structure of a society. Like the other approaches cognitive behavior therapy works with people who have some relationship problems in the family environment or couple relationships before marriage.

There are several models in treatment of couple and family conflicts. Although it was looked to cognitive behavior therapy method in this study, there are some other therapy approaches for solving family problems like conflicts, unacceptability, conditional love and lack of empathy between members. In this context, rational emotive therapy by Albert Ellis tried to solve relationship problems in 1950s. Ellis developed his approaches in the basis of family relationships firstly. After that when the date came to the 1980s behavior therapy and then cognitive behavior therapy was interested in the couple conflicts. Consequently, the roots of theoretical approach in the family therapy may reach to the Ellis's rational emotive therapy (Dattilio, 2010).

In a national survey was carried out by the American Association for Marriage and Couple Therapy (AAMFT), it was asked to family and couple therapists which therapy modal is their priority in the therapy process when they work with the family and couple conflicts. According to the results of survey the most used therapy modal was cognitive behavioral family therapy among 27 therapy approaches (Northey, 2002; cited from Dattilio, 2010). It can be enhanced this types of statistical survey results. Cognitive behavior therapy is one of the most effective approaches among therapy methods in the way of its empirical bases. This can be a factor that the modal is preferred by some part of therapists in the couple conflict and family relationships.

When Albert Ellis developed his theory rational emotive therapy in 1950s, the cognitions are in the heart of his therapy modal. The approaches were established for the marital problems. Ellis and his colleges suggested that relationship dysfunction occurs when an individual holds irrational or unreal beliefs against his partner and relation. When this negative cognitive process occurs, the individual has likely negative emotions such as anger or aggression. Naturally these emotions triggered individual's behavior towards to his partner negatively. In the end of this cognition, emotion and behavior process the relationship between partners has a vicious circle as a dysfunctional relationship and it goes on forever (Dattilio \& Epsteion, 2005). 
In addition to this, Family system theory can be seen as one of the most crucial methods in the recent times. The family system theory believes the individual can only be fully understood within the context of the larger family system. Like system theory, cognitive behavioral family therapy stresses that a change in one person in the system changes the other individual in the family. The main factor in the cognitive behavior approach is changing distortion beliefs in the family. Cognitive behavior family therapy hypothesizes that some of the most efficient way to change beliefs is through cognitive restructuring, rational analysis, and behavioral enactment. (Friedberg, 2006). Cognitive behavior approach is an effective intervention for at risk parenting behavior. However it is frequently integrated with other treatment approaches like schema therapy (Seligman \& Reichenberg, 2010).

\section{Cognitive behavioral couple and family therapy}

Although cognitive behavior therapy is an empirical and more preferable method in the treatment field, it may not be the most influential modal on the family and couple conflicts. Yet cognitive behavior therapy is powerful and successful when it integrates with appropriate modals during the treatment (Dattilio, 2010).

Patterson (2000), suggested that cognitive behavior theory can be evaluated by two patterns; one is behavioral couple therapy and the other is cognitive couple therapy approach. Behavioral couple approach focuses on the reactions that occurs after the presenting a behavior. At the end of this, desired behaviors are reinforced and undesired ones are punished by the authority figure. In this context, if a desired behavior is reinforced by the others, the behavior can frequently occur. If undesired behavior is ignored and punished by the authority, individuals do not present the behavior so much.

Jacobson and Margolin (1979), addressed to three basic points in the behavioral couple therapy:

Communication; listening, acceptance-taking and response.

Problem solving; respectful, collaborative and presenting systematical solutions to primary matters.

Changing the behavior; equality in the sharing tasks.

Consequently, behavioral couple therapy approach is not the most used therapy modal but it is common in the substance abuse Fals-Stewart, O'Farrell, Birchler, Córdova ve Kelley, 2005) and post-traumatic stress disorders (Monson, Fredman ve Adair, 2008). In addition to these it can be influent in some specific phobias between couples with reaction prevention and exposure technique.

Cognitive couple approach is based on the Beck's cognition modals in the fundamentals of depression. The schema has a quality of milestone in the Beck's cognitive therapy. Cognitive behavior approach defines the term of schema as cognitive structures that organize belief and perceptions. However schema has an important effect on the emotions and behaviors from the way of cognitive approach (Dattilio, 2005).

Schema was used by Jean Piaget with his accommodation and assimilation concepts in the field of developmental psychology in 1950s. After Piaget, in the work of attachment theory Bowlby and in the cognitive therapy Beck (1967) was used the schema term. Beck (1967) was used the schema on depressed individuals in order to change their negative beliefs about the self, the world and the future. Like Beck the latter researchers who were interested to cognitive behavior modality used also the schema in interpersonal relationships and this approach facilitated the family and couple therapy during the treatment 
process (Dattilio \& Epstein, 2005). Schema is also a third point of the triangle in the cognitive behavior therapy.

Cognitive behavioral couple therapists help family members become more active observers and evaluators of their own beliefs, work to change negative behavioral interactions to foster more positive thoughts and emotions about each other (Dobson, 2010). In cognitive behavioral family therapy, the family members are joining to the session together. Therefore the therapeutic focus pays attention to the nature of family members' distorted thoughts and behaviors (Friedberg, 2006).

Dattilio, Epstein and Baucom (2005) studied on the couple and family relationship in the context of cognitive behavior therapy. They adapted Beck's modal to the family structure and couple conflicts. According to this modal family members' cognitions have a key factor in the system and all members affect each other as a whole. Baucom and Epstein (2005) suggest five basic cognitive distortions that commonly affect couple and family relationships;

1. Selective perceptions of relational issues

2. Distorted attitudes or beliefs on the reasons of cases

3. Inaccurate expectations or suggestions of future events

4. Inaccurate assumptions about the general nature of relationships

5. Unrealistic standards to which the relationship is held (Osburn, 2011).

It is known that unconscious drives and childhood stages are crucial terms for psychodynamic theory in the treatment sessions. There is also some key words and terms for cognitive behavior approach. Some of them are cognition, behavior and distortion of beliefs.

Cognitive behavior therapy approaches to the couple treatment like other disorders such as depression, obsessive compulsive disorder. Yet there some differences are available among the couple therapy and the other psychological disorders. Initially couple therapy occurs both individually and more than one person. Since the relationship is essential between couples. Consequently relationship is among two or more people. Therefore sessions maintains with one or more than one person according to the treatment plan and sessions' structure. Therapist determines this with the clients mutually (Dobson, 2010).

\section{CONCLUSION}

Taking everything into consideration, cognitive behavior therapy is a good way in the treatment of psychological disturbances such as depression, panic and phobia etc. Yet it does not mean that it can be used for all disorders effectively. Family and couple therapy is one of them. Since family and couple relationships have also an emotional and complex construct in their inside. Cognitive behavior therapy cannot be effective for all the times with its systematical and structured modal. In other words all systems or structures are not proper for a specific disorder. For example same treatment plan cannot implement to the individuals who have same disorder or pathology. Yet every person carries a special characteristic and these features are different from each other. Nevertheless it can be a structural treatment plan for a couple sessions in the way of general framework if a therapist can use alternative techniques apart from outline. According to Dattilio (2010), the family background and cultural patterns 
should not ignore as a part of family establishment. So the family is not a rigid and mechanical relation in a way of positive or negative.

Even if cognitive behavioral therapy integrates with other modalities in the treatment of couple and family conflicts, some therapy approaches has not been associate with the CBT. For instance; solution focused therapy is one of them. Since solution focused therapy pays attention to the now and it ignores the family background. Whereas, the family is a whole building with its past, now and future (Dattilio, 2010).

Taking everything into consideration cognitive behavior therapy is an effective approach in the treatment of couple and family conflicts. Yet the cognitive behavior couple therapy should not be rigid in the implementation process on a specific couple therapy session. Certainly there may be a structural modal before any session but the structure may be flexible according to the relationship's positive side. In other words rigid techniques are not more important than client's wellness. Eventually this review study offers that cognitive behavior couple therapy is a good kind of treatment modal for couple and family relationships. Yet it is not a unique solution for people who have a relationship problems and conflicts.

\section{Reference}

Dattilio, F. (2005). The restructuring of family schemas: cognitive behavior perspective. Journal of Marital and Family Therapy, 31(1), 15-30.

Dattilio, F. M., \& Epsteion, N. B. (2005). Introduction to the special section: the role of cognitive behavioral interventions in couple and family therapy. Journal of Marital and Family Therapy, 31(1), 713.

Dattilio, F.M. (2010). Cognitive behavioral therapy with couples and families: A comprehensive guide for clinicians. New York: The Guilford Press.

Dobson, K.S. (2010). Handbook of cognitive behavior therapy (3rd ed.). New York, NY: The Guilford Press.

Dryden, W., \& Mytton, J. (1999). Four approaches to counselling and psychotherapy. USA and Canada: Routladge.

Friedberg, R. D. (2006). A cognitive behavioral approach to family therapy. Journal of contemporary psychotherapy, 36, 159-165.

Gurman, A. S. (2008). Clinical handbook of couple therapy (4th ed.). New York: The Guilford Press.

Leahy, R. L. (1996). Cognitive behavioral therapy: Basic principles and applications. U.S.A.: Institute for Cognitive Behavior Therapy.

Osburn, K. A. (2011). A cognitive behavioral approach to family counseling. Liberty University Online.

Padesky, C., \& Greenberger, D. (1995). Evinizdeki terapist: Klinisyen el kitabı. (D. Dağyaran, Çev.) İstanbul: Altın Kitaplar Yayınevi.

Seligman, L., \& Reichenberg, L. W. (2010). Theories of counseling and psychotherapy. Boston: Pearson. 